\title{
Winter Arctic Amplification at the synoptic timescale, 1979-2018, its regional variation and response to tropical and extratropical variability
}

\author{
Richard J. Hall ${ }^{1,2}$ - Edward Hanna ${ }^{1} \cdot$ Linling Chen $^{3}$ \\ Received: 29 June 2019 / Accepted: 3 October 2020 / Published online: 13 January 2021 \\ (c) The Author(s) 2021
}

\begin{abstract}
We investigate winter Arctic Amplification (AA) on synoptic timescales and at regional scales using a daily version of the Arctic Amplification Index (AAI) and examine causes on a synoptic scale. The persistence, frequency and intensity of high AAI events show significant increases over the Arctic. Similarly, low AAI events are decreasing in frequency, persistence and intensity. In both cases, there are regional variations in these trends, in terms of significance and timing. Significant trends in increasing persistence, frequency and intensity of high AAI events in winter are concentrated in the period 2000-2009, with few significant trends before and after this. There are some decreases in sea-ice concentration in response to synopticscale AA events and these AA events can contribute to the decadal trends in AA found in other studies. A sectoral analysis of the Arctic indicates that in the Beaufort-Chukchi and East Siberian-Laptev Seas, synoptic scale high AAI events can be driven by tropical teleconnections while in other Arctic sectors, it is the intrusion of moisture-transporting synoptic cyclones into the Arctic that is most important in synoptic-scale AA. The presence of Rossby wave breaking during high AAI events is indicative of forcing from lower latitudes, modulated by variations in the jet stream. An important conclusion is that the increased persistence, frequency and intensity of synoptic-scale high AAI events make significant contributions to the interannual trend in AA.
\end{abstract}

Keywords Arctic $\cdot$ Arctic Amplification $\cdot$ Climate change $\cdot$ Extreme weather $\cdot$ Synoptic $\cdot$ Reanalysis

\section{Introduction}

Electronic supplementary material The online version of this article (https://doi.org/10.1007/s00382-020-05485-y) contains supplementary material, which is available to authorized users.

Richard J. Hall

richard.j.hall@bristol.ac.uk

Edward Hanna

ehanna@lincoln.ac.uk

1 School of Geography and Lincoln Centre for Water \& Planetary Health, University of Lincoln, Think Tank, Ruston Way, Lincoln LN6 7FL, UK

2 School of Geographical Sciences, University of Bristol, Bristol, UK

3 Department of Earth Science, University of Bergen, Bergen, Norway
Many recent studies show that since around 1980 the Arctic has been warming at about twice the rate of hemispheric or global warming, termed Arctic Amplification or AA (e.g. Serreze and Francis 2006; Cohen et al. 2014; Overland et al. 2018; Davy et al. 2018). This is related to key feedbacks of global warming over the Arctic including the ice-albedo feedback (e.g. Deser et al. 2000), the ice-ocean heat flux feedback (Overland et al. 2015) the Planck radiation feedback (Pithan and Mauritsen 2014) and the lapse-rate feedback (Graversen et al. 2014). There have been a number of studies (e.g. Gong et al. 2017; Lee et al. 2017; Hao et al. 2019), that find that much of the warming trend is due to downward infra-red radiation, which in turn is linked to poleward moisture intrusions into the Arctic. It is notable that a number of studies find that AA occurs in model experiments in the absence of sea ice and snowcover changes, which suggests that mechanisms other than the ice-albedo effect might be significant (e.g. Graversen and Wang 2009). 
AA is greatest in autumn and winter where it is centred over the Arctic Ocean, while in summer it is much weaker and shifted over Arctic land masses (e.g. Serreze and Barry 2011; Cohen et al. 2018) due to different seasonal processes and key feedbacks operating in different locations and the ice-albedo feedback being absent over the ocean in summer. Arctic winter warm hotspots are located in extreme northern Canada, the Barents and Kara Seas and north of the Bering Strait (Fig. 1a) and Fig. 1b shows the vertical structure of zonal mean winter AA, with the familiar enhanced warming in the lower troposphere also extending to the lower stratosphere, where the warming trend increases compared with that for the upper troposphere. In summer, incoming solar
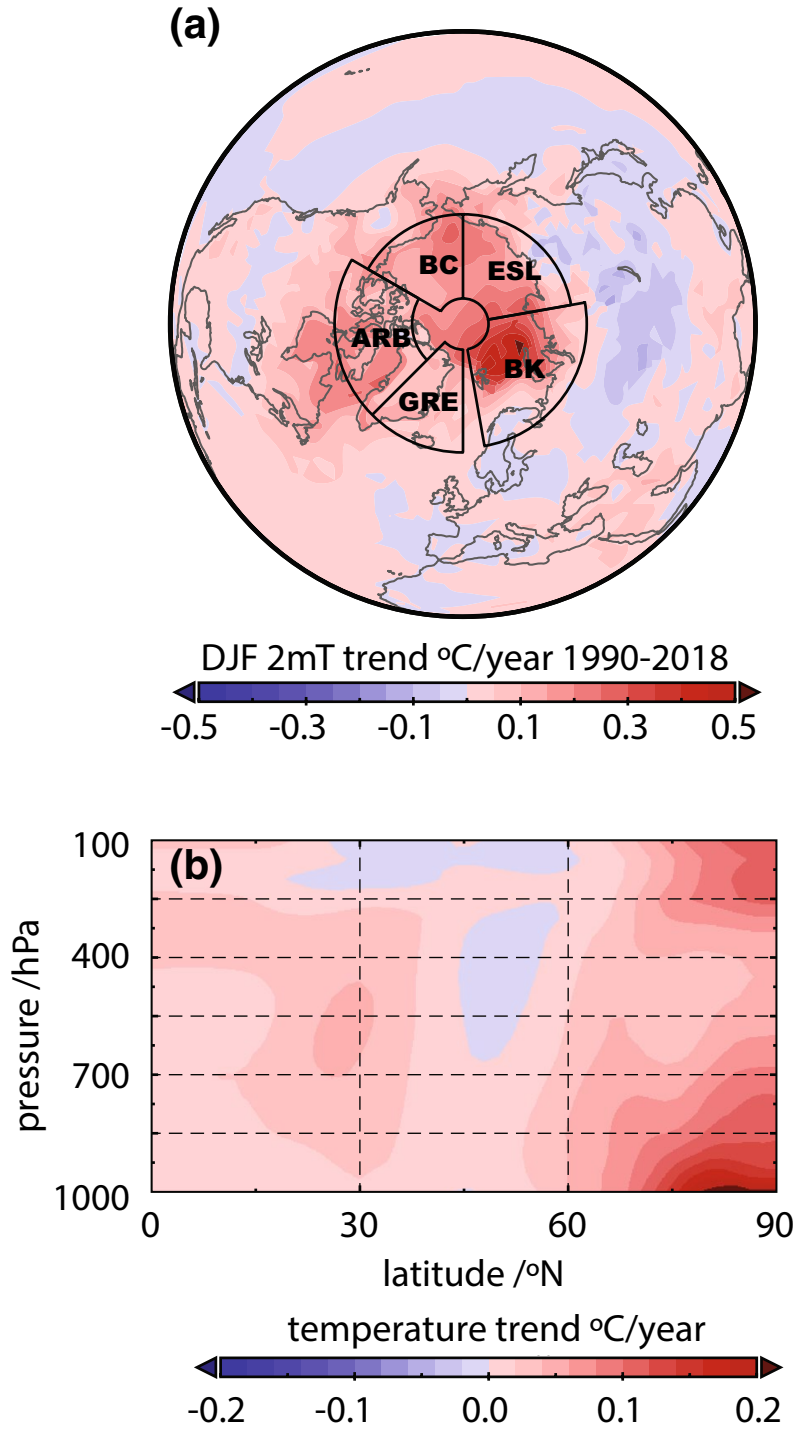

Fig. 1 Trends in (a) $2 \mathrm{mT}$ and (b) zonal mean temperature with altitude for winters 1990-2018, using ERA-I. The regions used to calculate regional AA indices are also shown in (a): $B K$ Barents-Kara Sea, ESL East Siberian-Laptev Sea, $B C$ Beaufort-Chukchi Sea, $A R B$ Canadian Archipelago, GRE Greenland Sea radiation melts ice and is absorbed by the open ocean, rather than warming the overlying air. This study focuses on the enhanced AA in winter.

Liu and Barnes (2015) identify Rossby wave breaking as a crucial mechanism which drives extreme moisture transport into the Arctic. However, further south in winter appreciable parts of Siberia and the central United States have been cooling on average between 1990 and 2018 (Fig. 1a) in a trend highlighted by Cohen et al. (2014), which has been linked to AA (e.g. Overland et al. 2015; Hanna et al. 2017) but has also been attributed to internal atmospheric variability (e.g. McCusker et al. 2016).

Many studies assess AA by examining trends in a range of parameters on decadal timescales, and frequently quantify such parameters in terms of anomalies (e.g. Screen and Simmonds 2010; Gong et al. 2017; Lee et al. 2017). While valid and presenting important findings, anomalies can potentially be misleading. For example, a positive heat flux anomaly could in fact represent a less negative than usual raw heat flux, and care must be taken with interpretation. Here we adopt a different approach, using anomalies for AA itself but using raw values of a range of parameters to better understand warm events on synoptic timescales in the Arctic.

AA has previously typically been measured on monthly or seasonal timescales. However, it is unclear how much interannual trends at these timescales are significantly influenced by synoptic-scale variability. Extreme AA events are fundamentally driven by strong regional heating, e.g. from ice or snow losses, or dynamical meteorology (circulation) forcing at the synoptic timescale, for example involving a split of the polar vortex and Atlantic/El Niño teleconnections (Overland and Wang 2016; Cullather et al. 2016), reinforced by the above-mentioned feedbacks. Here we examine AA on synoptic timescales and find that much of the trend in seasonal AA arises from Arctic warming events on such shortterm timescales, with changes in the persistence, frequency and intensity of these events making an important contribution to overall AA. We make links between the regional patterns and magnitude of extreme daily AA events and synoptic meteorological forcing and relate synoptic-scale AA events to different forcings from outside the Arctic. To our knowledge, this is the first systematic study of AA on synoptic timescales. In Sect. 2, we outline the datasets used, and Sect. 3 presents the methods. Results of the investigation are in Sect. 4, Sect. 5 is a discussion and there is a summary of the main findings in Sect. 6. 


\section{Datasets}

\subsection{Construction of AAI}

AA can be measured in a number of ways; either by trends in Arctic warming (e.g. Overland et al. 2018) or the difference in temperature anomalies between the Arctic and lower latitudes (Davy et al. 2018). Here we adopt the latter approach, as used in many other studies (e.g. Francis and Vavrus 2015), as trend analysis is not appropriate for daily data where interest is focused on rapid changes on synoptic timescales. AA datasets are typically based on monthly datasets such as Goddard Institute for Space Science (GISS) (Hansen et al. 2010) or HadCRUT4v (Morice et al. 2012) global temperature records, which effectively show gross-scale patterns and variations in AA (at monthly or longer timescales) but not shorter-term AA fluctuations and extremes. Recent improvements in reanalysis datasets make it viable to study AA properties and changes at shorter timescales. Here we construct and analyse a daily AA record 1979-2018 based on the European Centre for MediumRange Weather Forecasts (ECMWF) ERA-Interim (ERA-I) reanalysis (Dee et al. 2011). Using this dataset we analyse more detailed (higher-time-resolution) changes in AA over these 40 years. 6 -hourly $2-\mathrm{m}$ air temperature data $(2 \mathrm{mT})$ were used to calculate daily temperature means at the native $0.75 \times 0.75^{\circ}$ spatial resolution for the winter season (DJF). Area-weighted means were calculated for $60-90^{\circ} \mathrm{N}$ and for the whole Northern Hemisphere (NH). Daily temperature anomalies were then calculated for each region as the departure of a given day's temperature from the climatological mean of that day of year, based on the period 1981-2010. The daily AAI is defined as the difference between temperature anomalies over $60-90^{\circ} \mathrm{N}$ and those for the whole northern hemisphere. High AAI values are where the Arctic temperature anomalies are greater than for the hemisphere as a whole, while low AAI values indicate that Arctic temperature anomalies are lower than those for the whole hemisphere. For sensitivity analysis, an identical procedure was followed but this time for temperatures north of $70^{\circ} \mathrm{N}$ compared with the whole $\mathrm{NH}$. The correlation between the two daily time series $\left(60^{\circ} \mathrm{N}, 70^{\circ} \mathrm{N}\right)$ for $1979-2017$ is 0.81 . $60^{\circ} \mathrm{N}$ is used here as it follows previous work (e.g. Davy et al. 2018). The daily timeseries is dominated by fluctuations in Arctic temperature, as temperature variations over a whole hemisphere will be much less than for a smaller region like the Arctic. We also investigated indices based on the differences between $60-90^{\circ} \mathrm{N}$ and $0-60^{\circ} \mathrm{N}$, and $60-90^{\circ} \mathrm{N}$ and $30-60^{\circ} \mathrm{N}$, but found no appreciable differences in the timeseries. Although the daily Arctic Amplification Index (AAI) is based on previous work, it is not a full normalisation procedure. A problem with using a standardised index is that a method based on standardisation fails to capture the increases in Arctic warming relative to lower latitudes, as a standardised anomaly for lower latitudes is a much reduced absolute temperature value than at higher latitudes: thus while higher latitude absolute temperature anomalies increase more rapidly than at lower latitudes, the standardised anomalies can be of similar magnitude.

Several localised AA indices were also calculated. For distinct regions within the Arctic Ocean we used sectors identified by Screen (2017), where sea-ice variability in each region is largely independent of that in other regions (Fig. 1b). These are: Barents-Kara Seas (BK; $65-85^{\circ} \mathrm{N}$, $10-100^{\circ} \mathrm{E}$ ), East Siberian-Laptev Seas (ESL; $68-85^{\circ} \mathrm{N}$, $\left.100-180^{\circ} \mathrm{E}\right)$, Beaufort-Chukchi Seas (BC; $68-85^{\circ} \mathrm{N}$, $180-240^{\circ} \mathrm{E}$ ), Canadian Archipelago-Baffin Bay (ARB; $63-80^{\circ} \mathrm{N}, 240-315^{\circ} \mathrm{E}$ ) and Greenland Sea (GRE; $63-85^{\circ} \mathrm{N}$, $\left.315-360^{\circ} \mathrm{E}\right)$. For these indices, in line with Screen (2017) we discount the region north of $85^{\circ} \mathrm{N}$ in calculating the AA indices and note that the Canadian Archipelago region only extends to $80^{\circ} \mathrm{N}$, as polewards of this there is little variability in sea ice concentration, much of the sea-ice being multiyear ice where any response of sea-ice to AA would manifest as changes in growth rate rather than sea-ice concentration. ERA-I $2 \mathrm{mT}$ over the Arctic compares well both to observed surface temperatures and to HadCRUT4 (Simmons and Poli 2014), and its update by Cowtan and Way, (2014) and has been used in a number of Arctic climate studies (e.g. Lindsay et al. 2014; Graham et al. 2017; Wilton et al. 2017) and so is a logical choice for our daily AAI, although there is an acknowledged warm winter-time bias over sea-ice. As different processes operate over land and sea surfaces, land/ sea masks were also applied to the region polewards of $60^{\circ} \mathrm{N}$ and the $\mathrm{NH}$, to create separate AA indices for land and sea regions of the Arctic.

\subsection{Energy fluxes from ERA-I}

To examine regional differences in energy flux and daily AA, we use fluxes from ERA-I: sensible heat flux (SHF), latent heat flux (LHF) and their sum to give turbulent heat fluxes (THF), surface downward longwave radiation (DLR) and vertical integrals of northward heat transport (NHT) and northward water vapour flux (NWVT). The energy flux terms are accumulated values so we obtain daily totals by selecting timesteps 00:00 and 12:00 with steps equal to 12 $\mathrm{h}$, to get the accumulated totals at 12:00 and 24:00. A simple daily total was then calculated. This can be converted to $\mathrm{Wm}^{-2}$ by dividing the values by the accumulation time in seconds. Heat fluxes have a land mask applied, so values were calculated over the ocean only, to avoid mixed signals. NHT and NWVT were calculated as the quantities crossing the southern border of the sector, expressed as quantities per 
metre. These energy flux parameters are presented as raw data for reasons discussed above.

\subsection{Potential temperature on the dynamical tropopause}

To assist in interpretation of daily AA events, we also use potential temperature on the dynamical tropopause (the surface with a constant potential vorticity of two potential vorticity units ( $\theta$ on $2 \mathrm{PVU})$. Potential temperature is a conservative property of the atmosphere and allows the identification of Rossby wave breaking (RWB) events, which may be significant in the polewards transport of moisture (Liu and Barnes 2015). Previous studies (e.g. Thorncroft et al. 1993; Strong and Magnusdottir 2008) identified two types of wave breaking: cyclonic wave breaking (CWB) and anticyclonic wave breaking (AWB), which are used here.

\section{Methods}

\subsection{Trend analysis}

Trends are calculated using the non-parametric Sen slope test (Sen 1968) and significance of trends is calculated using the Mann-Kendall trend test, autocorrelation being accounted for using the pre-whitening method of Zhang (2000). Significant trends are identified as those where $\mathrm{p}<0.05$. In addition to calculating trends over the whole period, trends are also calculated for 11-year moving windows and results are shown for a range of p-values $(0.01$, $0.05,0.1)$.

\subsection{Composite analysis}

We present composite maps of $500 \mathrm{hPa}$ geopotential height (Z500) and $2 \mathrm{mT}$ differences between the 100 highest and lowest AAI days for the Arctic and each region. The significance $(\mathrm{p}<0.05)$ of any difference between composites is assessed with a two-sided t-test and the p-values are adjusted for field significance and multiple comparisons using the false discovery rate of Benjamini and Hochberg (1996).

\subsection{Markov chain analysis of frequency, persistence and intensity of AAI events}

We identify and analyse three different aspects of high or low AAI events on a synoptic timescale: frequency, persistence and intensity. Markov chain analyses (e.g. Wilks 2011; Kim et al. 2017a, b) were used to analyse changes in the frequency and persistence of more extreme AAI events with time. Daily time series were converted into dichotomous variables based on yes/no exceedance of specific daily
AAI thresholds, in this case, above the 90th percentile for high AAI days and below the 10th percentile for low AAI days. The specific thresholds vary according to season and region. A two-state Markov chain can be used to assess the frequency and persistence of such binary events, assuming serial independence within the season in question. The frequency of events is the number of events with the same consecutive state in a given period, so for example a single day would count as one event, as would a run of four consecutive days. Thus the number of groups where the threshold is exceeded is counted, not the individual days exceeding the threshold. The persistence of the occurrence groups is also considered and is defined as the average number of consecutive days per event as averaged across all events (groups). The intensity of events was identified by taking the ten highest and lowest AAI days within a season, and averaging these, to give an indication of how the most extreme AAI days within a season, both high and low, are changing over time.

\subsection{Evolution of high AAl events}

To examine the evolution of high AAI events on synoptic timescales we produce composites of energy fluxes, heat and water vapour transport, daily AAI values and sea ice concentration, based on the highest $5 \%$ of AAI days in winter (180 days), from 14 days before the maximum AAI to nine days after. These high AAI days are split into separate events, with the proviso that events (i.e. the dates of maximum AAI) should be at least ten days apart. This results in around 40 separate events for each Arctic sector. The ERA-I convention is that downward fluxes are positive.

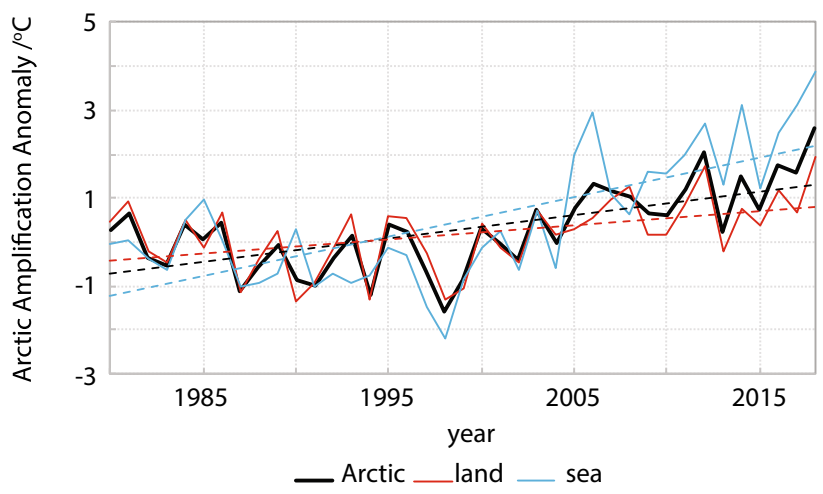

Fig. 2 Seasonal means of daily AAI values in winter for the Arctic, land and sea regions. Linear trends for each region are shown as dotted lines. Only significant trends are shown 


\section{Results}

\subsection{Frequency, persistence and intensity of high and low AAl events}

Seasonal means of daily AAI values for the Arctic, land and sea are shown in Fig. 2, while the equivalent for the Arctic sectors is Figure S1. All regions and sectors show an overall positive trend of increasing AAI values, although in some instances these are relatively slight and not statistically significant (e.g. the Beaufort-Chukchi seas, Figure S1). Trends for the Arctic, land and sea regions are significant. The daily land AAI has a strong, significant correlation with the Arctic AAI (0.93), but correlates more weakly, but still significantly, with the sea AAI (0.39). The sea AAI correlation with the Arctic AAI is significant but moderate $(0.70, \mathrm{DJF})$. Figure 3 shows that winter 11-year moving window seasonal trends are significant for years centred on 2001-2004 for the Arctic, Barents-Kara and East Siberian-Laptev sectors and the land and sea regions, and significant trends in the Beaufort-Chukchi Seas extend from 2002 to 2006 $(\mathrm{p}<0.1)$; however, the significant trends arise earlier for

\begin{tabular}{|l|l|l|l|l|l|l|l|l|l|l|l|l|l|l|l|l|l|l|l|l|l|l|l|l|l|l|l|l|l|l|}
\hline Arctic & & & & & & & & & & & & & & & & & & & & & & & & & & & & & \\
\hline land & & & & & & & & & & & & & & & & & & & & & & & & & & & & & \\
\hline sea & & & & & & & & & & & & & & & & & & & & & & & & & & & & & \\
\hline
\end{tabular}

Fig. 3 Significant positive (brown) and negative (blue) 11-year trends for seasonal means of daily AAI values. Year is the centre of the window. Significance of trend is $\mathrm{p}<0.01$ (dark); $\mathrm{P}<0.05$, (medium); $\mathrm{p}<0.1$ (light)

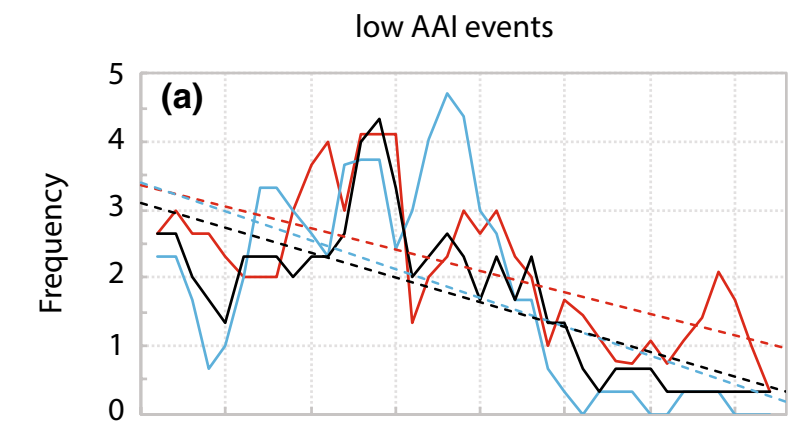

high AAl events
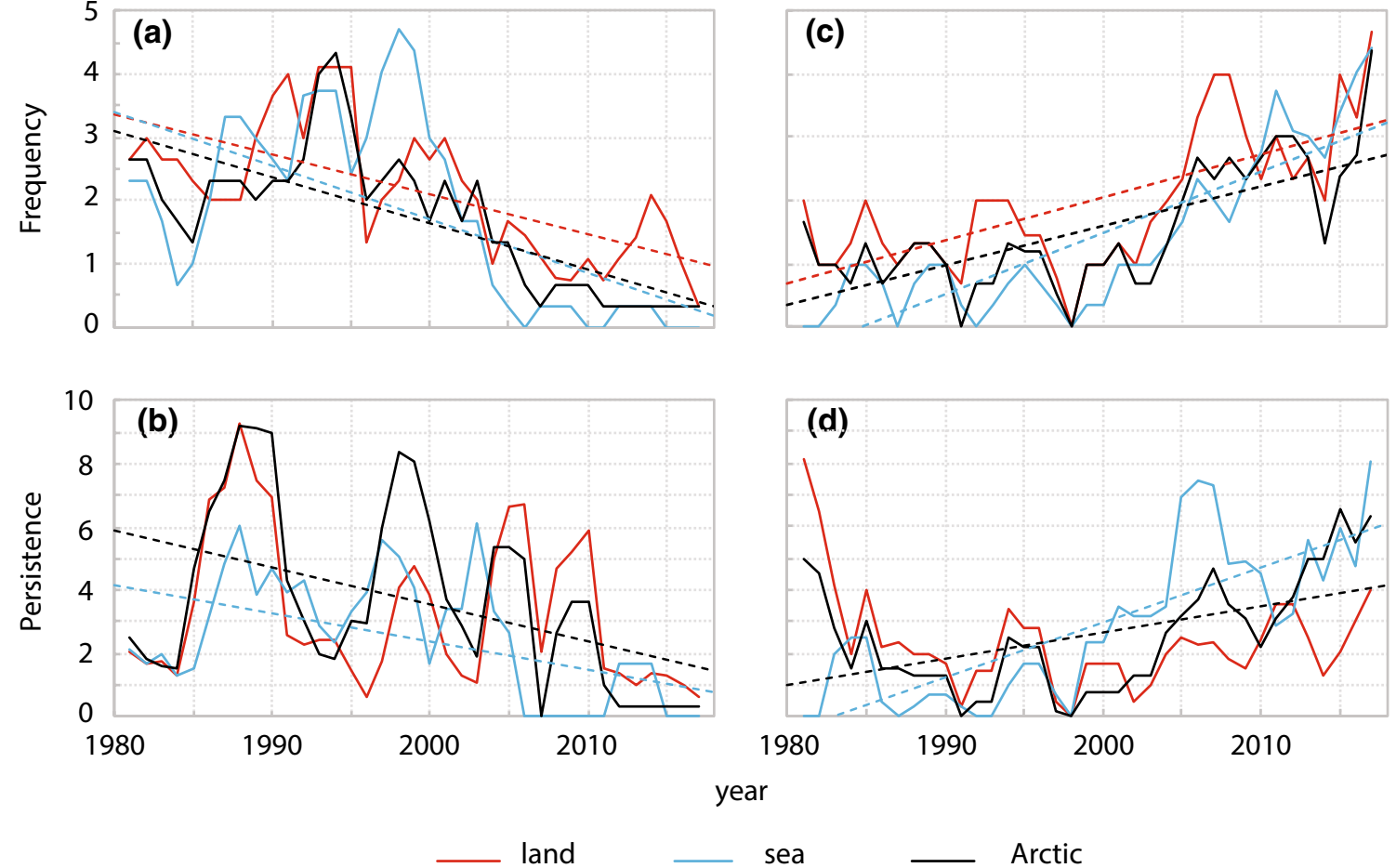

Arctic

Fig. 4 Persistence and frequency of high and low AAI events, winter 1980-2018 for the Arctic, land and sea regions. Time series are smoothed with a 3 -year moving average. Linear trends found to be significant using the unsmoothed time series are shown as dotted lines 
the Canadian Archipelago (1994-1999). Interestingly there are few significant trends in the period after this.

\subsubsection{Frequency and persistence of AA events}

Figure 4 shows the frequency and persistence of high and low AAI events for winter for the Arctic, land and sea regions, identified using Markov chain analysis. Figure S2 shows the same for the Arctic sectors. There are significant decreases in the frequency of low AAI events for the Arctic, land and sea regions and significant decreases in low AAI event persistence in the Arctic as a whole and over the sea (Fig. 4a, b). The Arctic, land and sea regions all have significant increases in frequency of high AAI events, while significant increases in persistence of high AAI events are found for the Arctic and over the sea (Fig. 4c, d). In the Arctic sectors, significant negative trends in frequency (persistence) of low AAI events occur for the Barents-Kara and Greenland (East Siberian-Laptev) Seas (Figure S2a,b). Positive significant trends of high AAI events occur only for frequency (Barents-Kara, East Siberian-Laptev, Greenland; Figure S2c). The Beaufort-Chukchi seas and Canadian Archipelago present an interesting contrast. There are no significant trends in either persistence or frequency of high and low AAI events. However, interannual variability in frequency of low AAI events is much higher than for the other sectors, while interannual variability in persistence of low AAI events is very low (Figure S2). Low AAI events for these regions are characterised by a high frequency but short persistence, events being often restricted to single days. The pattern for high AAI events is similar to those from other sectors.

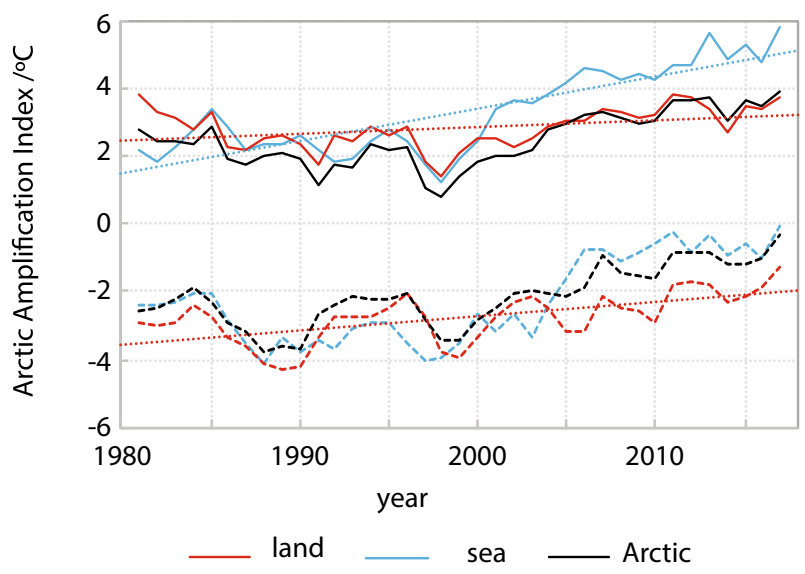

Fig. 5 Intensity of high (solid lines) and low (dashed lines) AAI events for Arctic, land and sea regions, smoothed with a three-year moving average. Only significant linear trends are shown (dotted lines), calculated from the unsmoothed time series

\subsubsection{Intensity of AA events}

AAI event intensity is presented in Fig. 5 for the Arctic, land and sea regions, and in Figure S3 for the other sectors. There are significant positive trends over land for both low and high AAI events, that is both tails of the distribution are showing a significant shift towards more positive values, so extreme cold events are becoming less intense while extreme warm events become more intense. The only other significant trend is a positive trend of high AAI values over the sea. Here the high AAI events become distinct and consistently higher than those for the Arctic and land regions around 2000 (Fig. 5a). Since 2012, there has been a decrease in both high and low AAI events, which is most marked over land. The intensity time series for the Arctic sectors show significant trends for GRE for both high and low events (Figure S3). ESL shows positive trends for both high and low AA events, while there are further positive trends for low events in BK and BC (Figure S3a).

\subsubsection{Trends in persistence, frequency and intensity}

All time series of frequency, persistence and intensity are very noisy, showing greater interannual variability than the magnitude of the overall trend, and a linear trend does not always appear to be the best fit. For example, in the Arctic as a whole, the frequency of high AAI events appears to have little trend prior to 2000, then shows a marked increase to around 2010 before flattening off again (Fig. 4c). To further analyse trends of persistence and frequency and intensity, 11-year moving window trends were calculated and are shown in Fig. 6. Significant trends for low (high) AAI events mostly show decreases (increases) in frequency, persistence and intensity. The most significant winter trends for the whole Arctic, land, sea, Barents-Kara and East SiberianLaptev Seas are concentrated between 2001 and 2009, while other Arctic sectors show very few or no significant trends. There are some outliers for the Arctic, Barents-Kara and East Siberian-Laptev Seas in the 1980s and early 1990s, including a number of 11-year trends of opposite sign to those which would be expected from the overall time series. For example, in the 1980s the Arctic shows significant increases (decreases) in the persistence of low (high) AAI events. For the Arctic, land and sea, significant decreases in persistence, frequency and intensity of low AAI events occur earlier than the significant increases in high AAI events (1998-2004 cf. 2000-2008, Fig. 6), while for the Arctic sectors, they are more synchronous (Figure S4). 


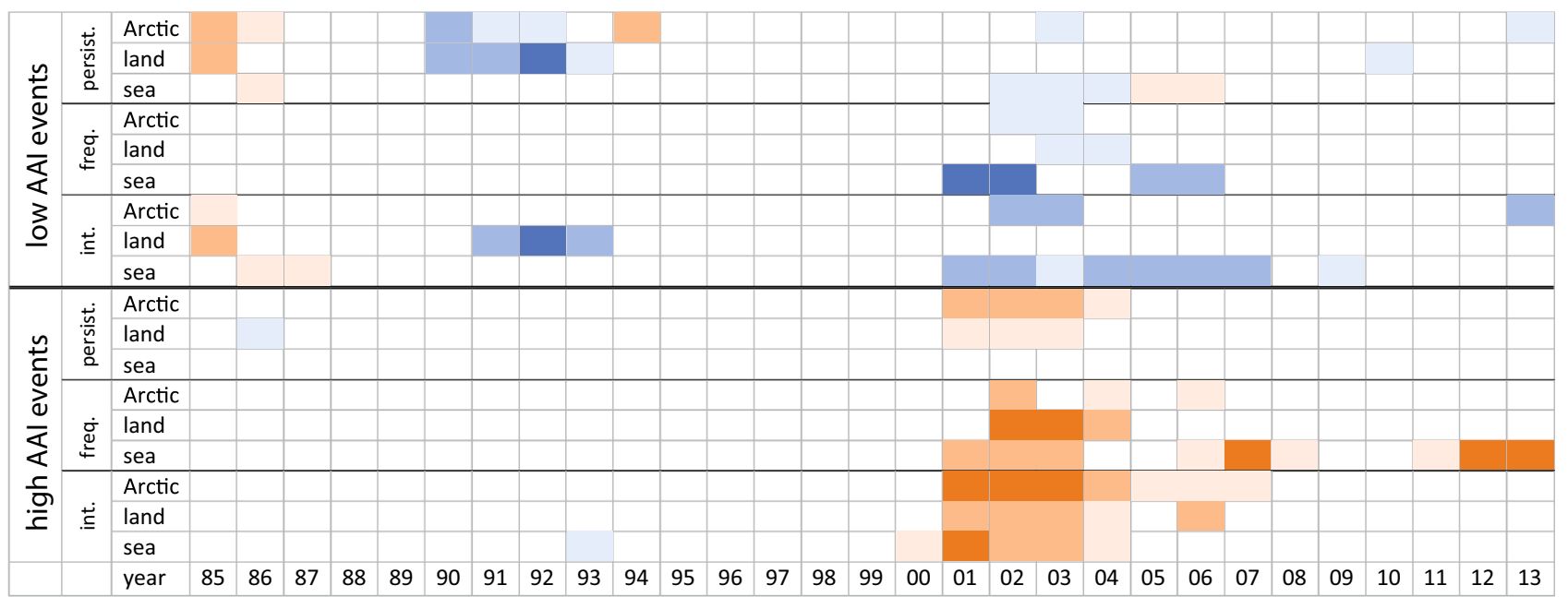

Fig. 6 Significant decreasing (blue) and increasing (orange) 11-year moving window trends for persistence, frequency and intensity of high and low AAI events for the Arctic, land and sea regions. Significance: $\mathrm{p}<0.01$ (dark); $<0.05$ (medium); $\mathrm{p}<0.1$ (light)
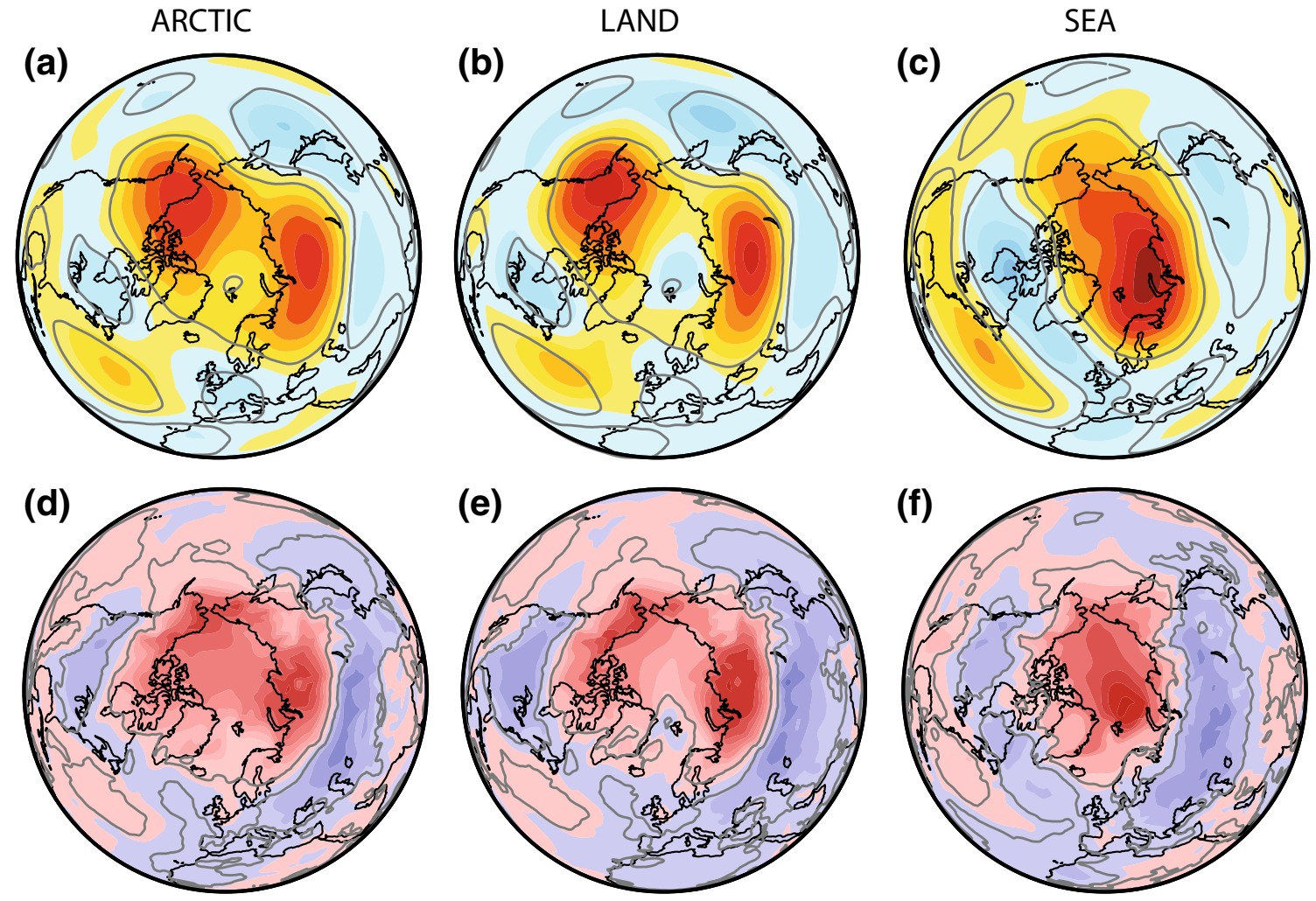

Z500 difference $/ \mathrm{m}$

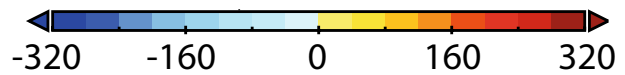

$2 \mathrm{mT}$ difference $/{ }^{\circ} \mathrm{C}$

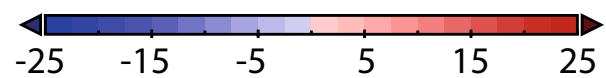

Fig. 7 Composites of 100 highest minus 100 lowest AAI days, 1979-2018. a-c Z500, d-f: 2mT for the Arctic, land and sea regions 


\subsection{Spatial variability of $\mathrm{Z500}$ and $2 \mathrm{mT}$ during high and low AAI events}

Composite plots of Z500 and $2 \mathrm{mT}$ for the 100 highest AAI days minus the 100 lowest AAI days for the 40 years are presented for the Arctic, land and sea regions (Fig. 7) and for the sectoral AAIs (Figure S5). These show some notable differences between regions in the locations of temperature and Z500 maxima and minima. For all regions and sectors the composite differences in Z500 are co-located with areas of significant high (low) $2 \mathrm{mT}$ differences. Where the two sets of anomalies agree one can assume that Arctic surface heat anomalies are probably more strongly related to and driven by dynamical (circulation) changes, while near-surface temperature anomalies that are unrelated to thickness anomalies may have resulted from more localised/shallower heat sources such as sea-ice removal increasing turbulent heat flux from the ocean. Here comments concern high AAI days: the converse is true for low AAI days.

For the Arctic, significant areas of increased Z500 heights occur over Northern Siberia and centred on the north coast of Alaska, with a region of significant height increase over the central North Atlantic Ocean (Fig. 7a), while longitudinally extensive regions of significantly lower heights extend around the mid-latitudes. Significant positive temperature anomalies occur over the central Arctic and the northern coasts of Siberia and North America, with cold anomalies stretching east-west over a broad swath of central Eurasia and extending southeast from southwest Canada across much of the central USA (Fig. 7d). This is the well-established Warm Arctic-Cold Continents pattern (Overland et al. 2011; Chen et al. 2018) and generally corresponds with midtropospheric height anomalies (Fig. 7a). The land-based AAI events show a very similar pattern to those of the Arctic as a whole (Fig. 7b, e), indicating that the more extreme Arctic AAI days, both high and low, occur over land (54\% shared high days, $80 \%$ shared low days), rather than over the sea (32\% shared high and low days). The sea-based AAI shows a monopole of high Z500 anomalies centred over the Kara Sea, but extending eastwards to the Bering Strait (Fig. 7c). The $2 \mathrm{mT}$ anomaly is centred slightly to the North of the Z500 centre, closer to Svalbard (Fig. 7f). Low heights over the UK and western Scandinavia coupled with high heights over north Siberia, and a similar pattern of low heights south of Bering Strait and increased heights over Alaska, indicate the transfer of warm southerly air masses right up into the central Arctic (Fig. 7a-c). Temperature and GPH differences over Greenland, although significant, are more modest than those found over Siberia and Alaska in winter.

Figure S5 show patterns for the locations of Z500 and $2 \mathrm{mT}$ anomalies for the Arctic sector AAIs. Z500 anomalies occur at largely within the sector concerned, as do $2 \mathrm{mT}$ anomalies although these are often located where warmer air flow anticyclonically around the Z500 anomaly, indicating higher surface pressure. For the Canadian Archipelago, $2 \mathrm{mT}$ anomalies, while significant, are weaker than for other sectors, which, due to the location of the sector away from the Arctic gateways, means more limited advection of warm air.

\subsection{Energy fluxes for high AAI events}

Figure 8 shows lead-lag composites for high AAI events, illustrating changes in energy fluxes before and after the maximum AAI day. THF are consistently positive (downward) for the East Siberian-Laptev and Beaufort-Chukchi sectors (Fig. 8a), peaking two days before the AAI maximum (AAmax). THF for other regions are negative (upwards), the upwards flux being greatest at maximum leads and lags, when the vertical temperature and moisture gradients between surface and atmosphere are greatest. This upwards flux diminishes at AAmax as the vertical temperature gradient is reduced. Further reductions in upwards flux will arise as the air overhead contains more moisture, reducing the upward latent heat flux (not shown). The distinction here between positive and negative THF regions is between areas with high sea ice concentration (SIC), which reduces or prevents upwards turbulent heat fluxes from the ocean surface (East Siberian-Laptev and Beaufort-Chukchi sectors), and those with a higher proportion of exposed ocean, where upwards THF are less restricted in larger areas of the sector.

DLR is much greater for the Greenland and Barents-Kara Seas (Fig. 8b), associated with greater quantities of water vapour in the atmosphere and the passage of extratropical cyclones into the regions from lower latitudes, although the amplitude of the increase at AAmax is less than that in the Beaufort-Chukchi and East Siberian-Laptev Seas. As with THF, the minimum amplitude is for changes in the Canadian Archipelago. This is likely related to limited cyclone activity. Figure S5g shows that for AAI high events in this sector, the usual route of storms into the Arctic via Baffin Bay is blocked by anticyclonic anomalies.

NWVT is greatest over the Greenland Sea, this sector showing the greatest magnitude of increase at AAmax (Fig. 8c). The Beaufort-Chukchi Seas also shows a marked increase peaking just prior to AAmax. These two regions are in close proximity to the oceanic gateways into the Arctic (Greenland-Norwegian Seas and Bering Strait respectively), which will provide access for moisture transport into the Arctic by cyclones. In the East Siberia-Laptev seas, NWVT is actually slightly negative (southwards), from -5 to +5 days.

NHT is highest for the Greenland Sea (Fig. 8d), showing large increases peaking at AAmax, likely associated with Greenland blocking and synoptic-scale storms. For other regions, a more complex picture emerges. For the East Siberian-Laptev Seas, NHT declines to a minimum at AAmax, 

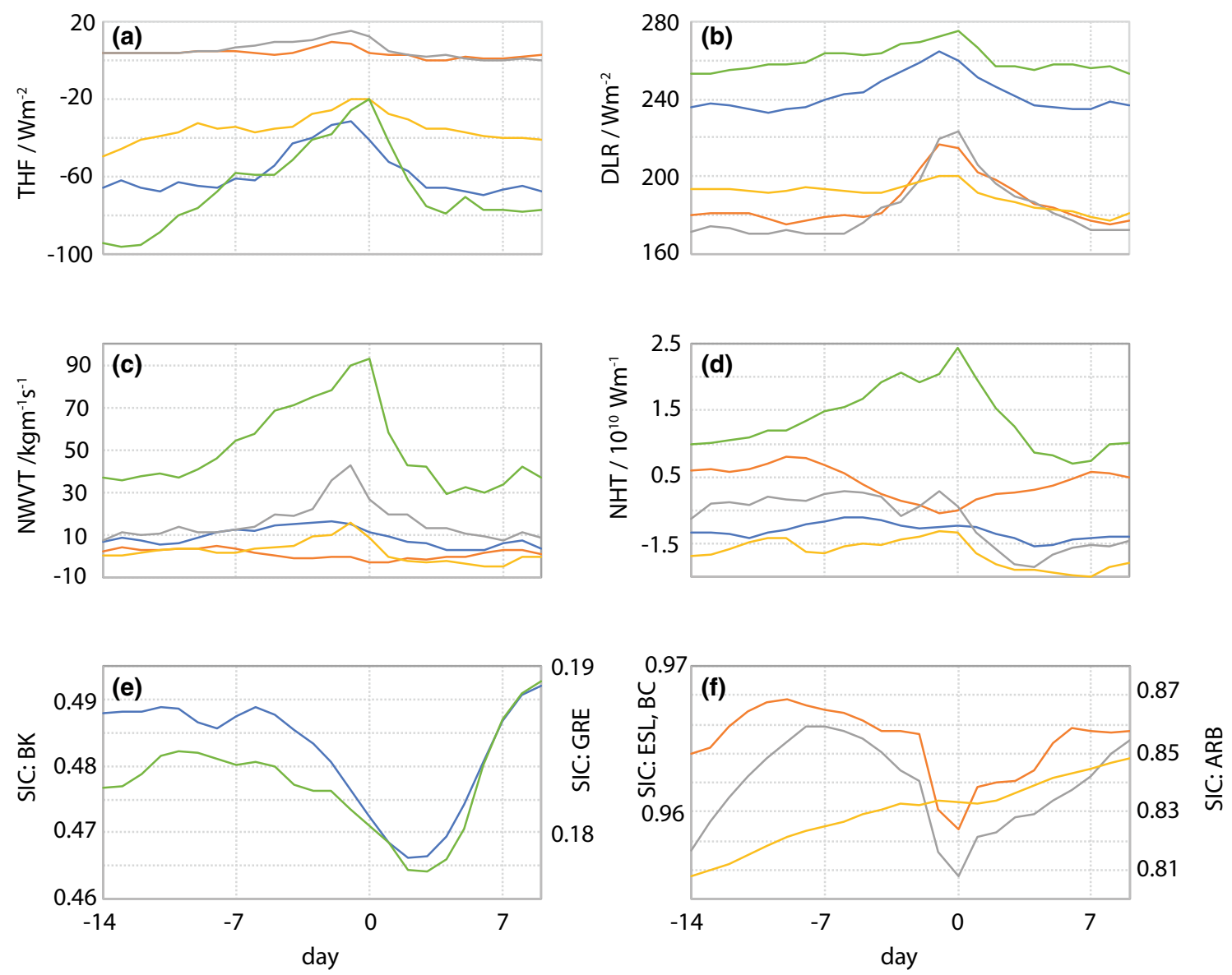

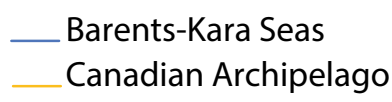

Fig. 8 Composites of (a) turbulent heat fluxes (b) total DLR (c) northward water vapour transport $(\mathbf{d})$ northward heat transport $(\mathbf{e}, \mathbf{f})$ sea-ice concentration (SIC) at lead times up to 14 days prior to maxi-

while for the Canadian Archipelago and the Barents-Kara Seas it is consistently negative. In the Beaufort-Chukchi Seas there is peak in NHT at d-1, after which values become negative.

These regional differences in energy and moisture flux are reflected in SIC responses at AAmax. The Beaufort-Chukchi and East Siberian-Laptev Seas demonstrate a similar SIC response; initial growth at longer lead times, reflecting the seasonal cycle of ice growth, followed by a sharp decline in SIC from d-2, with a sea-ice minimum at AAmax as a response primarily to increased DLR (Fig. 8b), followed by a steady recovery in SIC (Fig. 8f). The Greenland and Barents-Kara Seas on the other hand show a more gradual but extended SIC decline from d-6, and the minimum is not reached until 2 days after AAmax (Fig. 8e). Here, while DLR plays an important role in SIC reduction, contributions from NHT and NWVT for the Greenland Sea are mum AAI value, and lags up to 9 days. Derived from 5\% high AAI days in each sector (180 days), split into separate events

particularly important. SIC in the Canadian Archipelago, on the other hand, as with the energy and moisture flux terms, behaves completely differently. Over the whole period there is a steady increase in SIC reflecting the growth phase of the annual cycle. However, from $d-3$ to $d+1$, this growth is halted, when AA max occurs, although actual reduction in SIC is minimal. After this, the growth cycle resumes. This is the one region where moisture intrusion is lower; with the exception of along the east coast of Greenland, net moisture transport over the archipelago is often southwards (Woods et al. 2013) and the peak in DLR is smaller than for all other regions. $2 \mathrm{mT}$ temperature anomalies are modest compared with other regions (Figure S5g), resulting in a cessation of SIC increase rather than the reduction seen elsewhere. 
d-6

(a)
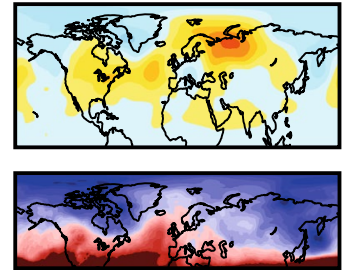

(b)

ESL
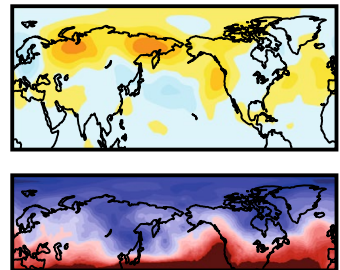

(c)
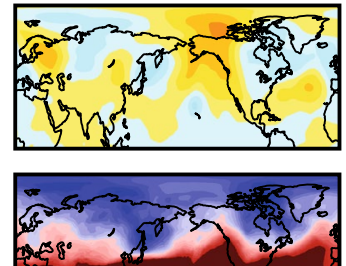

(d) ARB
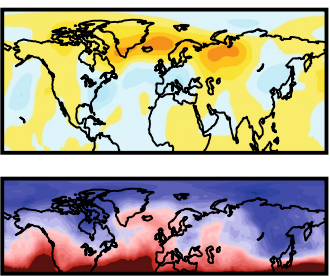

(e)

GRE
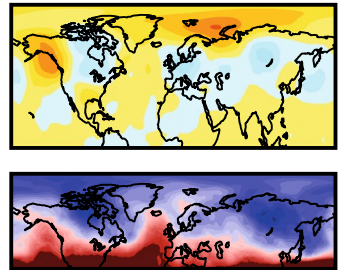

Z500 anomaly /m

$\begin{array}{lllll}-320 & -160 & 0 & 160 & 320\end{array}$

Fig. 9 Lagged composites Z500 anomaly and potential temperature on 2PVU, for 10 highest winter AAI events in the Arctic sectors. d-6, $-4,-2$, are 6-, 4- and 2-day lead times and d0 is the high AAI day.

\subsection{Sources of AA in winter}

From the above, differences between Arctic sectors are apparent, which may indicate different sources of forcing d-2
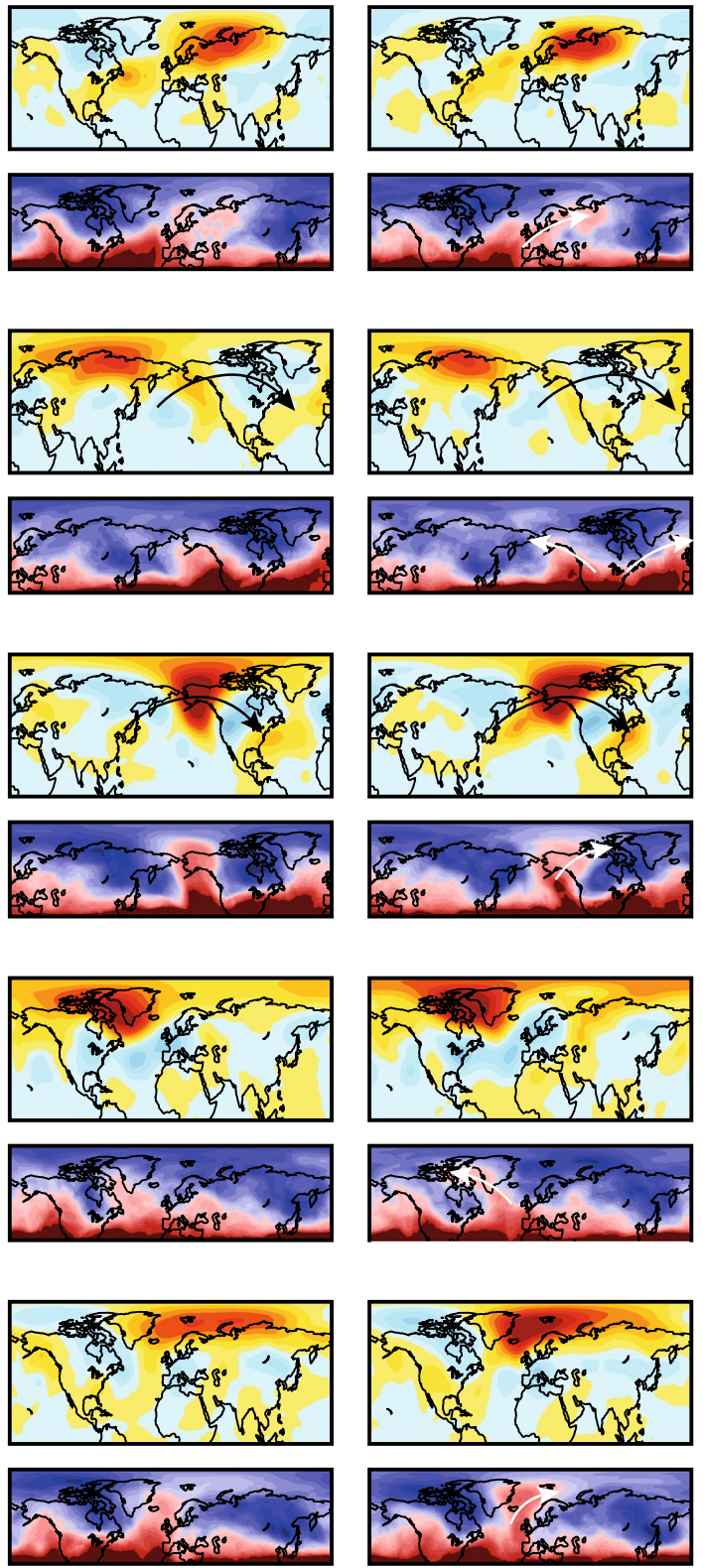

potential temperature $/ \mathrm{K}$

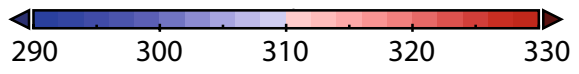

Note for ESL and BC maps are centred on $180^{\circ} \mathrm{W}$. Black arrows on Z500 for BC and ESL indicate location of wavetrains. White arrows on 2PVU panels indicate direction of Rossby wave breaking

for high AAI events. Examining Z500 anomalies and $\theta$ on 2PVU can help to explain these differences (Fig. 9).

For high AAI events in the Barents-Kara sector, over lead times from $\mathrm{d}-6$ to $\mathrm{d} 0$ a positive $\mathrm{Z} 500$ anomaly develops over 
the Kara Sea coast of Siberia, on the eastern side of the storm track into the Arctic, at the same time as the development of anticyclonic Rossby wave-breaking (AWB) over northwest Siberia and Scandinavia (Fig. 9a). East SiberianLaptev Sea high AAI events show positive Z500 anomalies along the northern coast of Siberia, which coalesce over the Taymyr Peninsula at d0. Z500 anomalies reveal evidence of a wavetrain over the North Pacific and North America. AWB takes place further south and west, over western Europe, but there is also a suggestion of cyclonic wave breaking (CWB) developing over the eastern Pacific (Fig. 9b). For the Beaufort-Chukchi seas, the development of increased Z500 anomalies over Alaska is accompanied by a wavetrain with low heights over the western US and Canada and increased heights over the eastern US. This is accompanied by CWB along the western seaboard of North America (Fig. 9c). For the Canadian Archipelago, positive Z500 anomalies grow over Baffin Bay and eastern Greenland from d-6 to d0 accompanied by clear CWB over the north Atlantic and up into Baffin Bay (Fig. 9d). Finally, for high AAI events in the Greenland Sea, positive Z500 anomalies develop over the Barents Sea and shift westwards, over the Norwegian Seas by d0, with AWB over the North Atlantic (Fig. 9e).

\section{Discussion}

For the Arctic as a whole, and over the Arctic seas the frequency, persistence and intensity of high (low) AAI events have increased (decreased) over the time period, although this masks considerable regional and temporal variations. There are few significant trends over land, and for the Arctic sectors, changes in persistence, frequency and intensity can be differentiated for the western and eastern Arctic. In the western Arctic (Beaufort-Chukchi Seas and the Canadian Archipelago) there are no significant trends in frequency, persistence and intensity for either season, with the exception of a decrease in intensity of low AAI events in the Beaufort-Chukchi sector. In addition, these regions reveal distinct differences in patterns between low and high AAI events; the frequency of low events shows no overall trend and high interannual variability, while the persistence again has no overall trend and very low persistence. This indicates that low AAI events for these two regions comprise frequent short-lived events, often consisting of individual days. In the eastern Arctic, significant winter trends are common in the Barents-Kara and East Siberian-Laptev Seas. This difference between trends in the eastern and western Arctic may indicate different sources of AA, further discussed below.

It is notable that the significant trends of increasing high AAI events for winter occurs in a window from 2000 to 2009. During this time, Arctic sectors, the Arctic and land and sea regions show significant increasing trends in persistence, frequency and intensity and the seasonal daily mean AAI. The exceptions here are the Canadian Archipelago and Greenland Sea, which show very few significant trends in high AAI events during the period, and for the archipelago the increase in seasonal means occurs between 1994 and 1999. This coincides with changing trends in the North Atlantic Oscillation (NAO). During the 1990s the NAO had a negative trend, and it can be seen from Figure S5g that in winter, high AAI in ARB is associated with a negative NAO. To try to explain some of these regional differences, we look at the wider patterns in the atmospheric circulation at high AAI events (Fig. 10).

In winter for eastern Arctic sectors (Barents-Kara, East Siberian-Laptev and Greenland Seas), the standard winter SLP tripole pattern of Siberian High, Icelandic and Aleutian Low is evident (Fig. 10a, d, m). For AAI high events in the Barents-Kara sector the Siberian High is zonally extensive, while for the East Siberian-Laptev sector the Siberian high is contracted zonally, centred on Mongolia. For AAI high events over the Greenland Sea a ridge of high pressure extends further westwards into the Eastern Atlantic, which displaces the Icelandic low, shifting it eastwards over Greenland. In addition there is a clear ridge of higher $500 \mathrm{hPa}$ geopotential heights over the North Atlantic (Fig. 10n). This configuration results in a strong meridional pressure gradient across the North Atlantic, and a stronger, more meridionally tilted jet stream (Fig. 10o), which steers synoptic-scale storms into the Arctic along the east coast of Greenland. This accounts for the very high NWVT associated with Arctic warming in the Greenland Seas sector. A similarly strengthened jet is seen for the Barents-Kara sector (Fig. 10c), but additional southerly winds entering the region are a result of anticyclonic winds blowing around the high pressure in central Siberia. These winds, although southerly, pass over land and therefore NHT and NWVT are reduced. In addition, the direction of winds indicates that moisture and heat are advected into the sector from the west, which would also account for the reduced poleward transports.

Zhong et al. (2018) identify eastward moisture transport into the Barents-Kara region from the Greenland Sea, although this is not the main contributor to moisture in the Barents-Kara sector. For the East Siberian-Laptev sector, wind strengths increase zonally along the maximum zonal pressure gradient parallel to the north Siberian coast. The air originates from the ice-covered Arctic Ocean (Fig. 10f) and so will transport reduced moisture and heat, accounting for the decrease in heat and moisture transport at AAmax over this sector. Here heating is from a marked increase in DLR which may be linked to an eastwards transport of water vapour and heat. The Beaufort-Chukchi Seas and Canadian Archipelago show more marked departures from the usual tripole pattern, with additional high-pressure regions over 

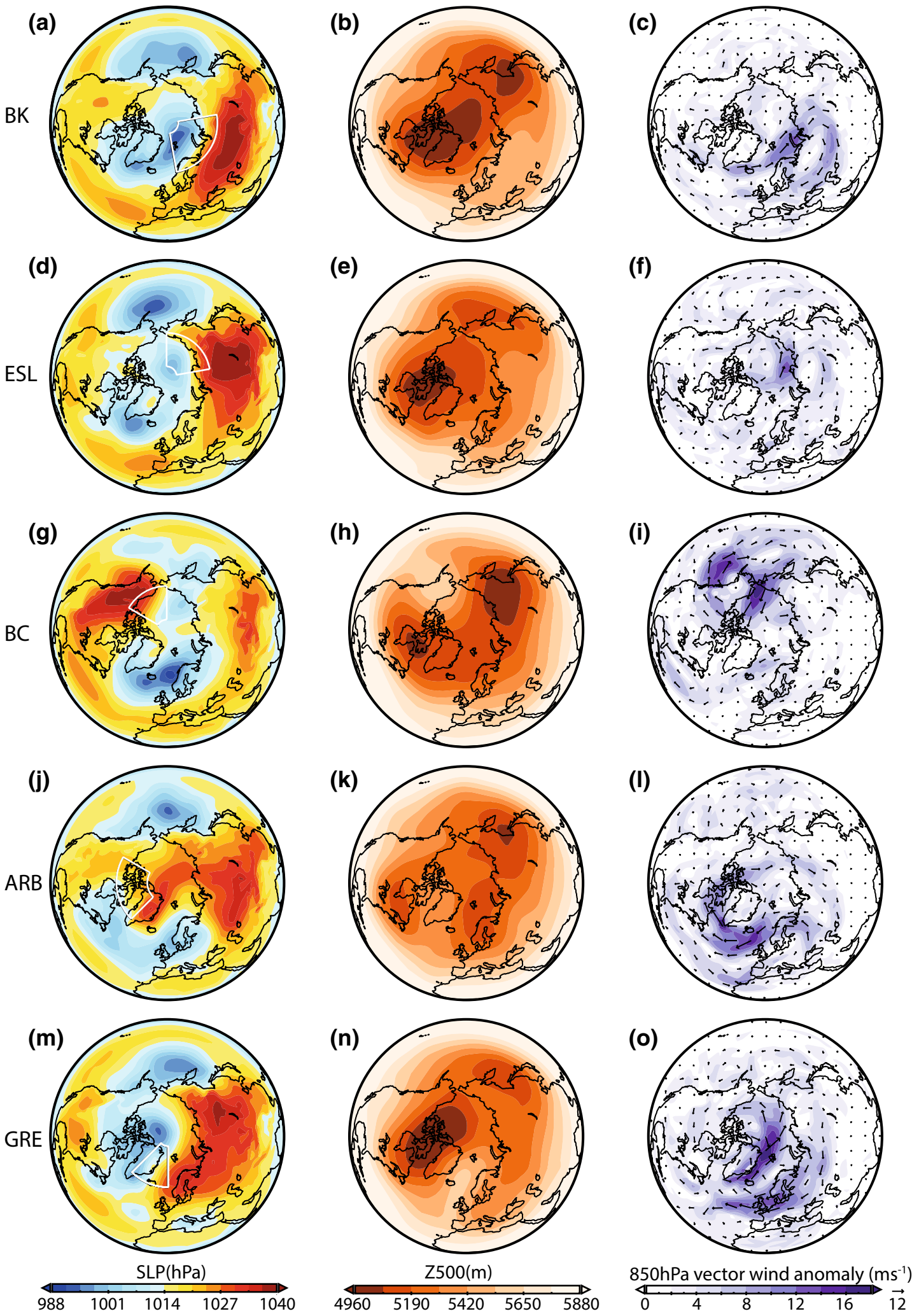

Fig. 10 Winter mean SLP, Z500 and anomaly of $850 \mathrm{hPa}$ vector wind, for 10 highest AAI events for different Arctic sectors indicated by row 
Alaska and Greenland respectively (Fig. 10g, j). There are clear ridges present in the Z500 fields over Alaska and Greenland (Fig. 10h, k). For the Beaufort-Chukchi sector the Alaskan high causes the Aleutian low to contract zonally, and to be displaced westwards. This creates a strong meridional pressure gradient across the Bering Strait, strengthening the southerly winds (Fig. 10i) and enabling cyclones from the Pacific storm track to intrude into the Arctic through the Bering Strait. This explains peak in NHT and particularly NWVT seen in Fig. $8 \mathrm{c}$ and d, which will contribute to the increased DLR in Fig. 8b. For the Canadian Archipelago, the high pressure over Greenland displaces the Atlantic jet southwards (Fig. 101), and weakens it, producing a negative NAO pattern. Anomalous anticyclonic circulation results in colder air moving southwards along the east coast of Greenland, before anomalous southeasterly winds over Baffin Bay bring relatively low amounts of NWVT and NHT into the sector, contributing to modest warming.

These atmospheric circulation patterns, together with the widely different sea ice coverage in the sectors, explain the disparate SIC variations seen in Fig. 8e, f. The Greenland and Barents-Kara Seas are more marginal ice zones, with greater extents of open water and a greater extent of seaice edge. SIC here is more sensitive to the large increases in DLR, causing melt. Additionally, the progress of storms through the sectors will result in windblown mechanical reductions in sea ice coverage. This will contribute to the observed lag, with continued strong winds further reducing SIC after the peak of the AAI event as in agreement with results from other studies (Park et al. 2015; Woods and Caballero 2016). For the East Siberian-Laptev and Beaufort-Chukchi Seas however, SIC is very high during winter. There is a rapid response, but SIC only falls by around $1 \%$. There is little sea-ice edge so the response is thermodynamic, coinciding with the AA maximum, followed by a quick recovery as temperatures increase again. In the Canadian Archipelago, SIC does not decrease. This is because in this sector, ice concentration is still increasing rapidly, so the warming has the effect of halting growth rather than resulting in an actual reduction. What is notable in all cases is that SIC responds to the high AAI event, rather than the other way round, and contributions from turbulent fluxes which would be consistent with the ice-albedo feedback, are minimal, when averaged over the sectors. Particularly in the Atlantic, but also at the Bering Strait, it is the tracking of cyclones into the Arctic that causes the synoptic-scale high AAI events. This is in agreement with other studies, which find the Atlantic sector is an important location for northward heat flux, both oceanic and atmospheric, via the Nordic seas (Graversen et al. 2008; Graham et al. 2017): therefore it is plausible that high winter AAI years in this sector, and in the Arctic as a whole, are driven by years with high northward heat flux, either atmospheric or oceanic. For example, in winter 2016 several notable Atlantic storms penetrated into the Arctic, leading to significant warming episodes (Cullather et al. 2016; Kim et al. 2017a, b). Increased frequency and duration of winter warming events since 1979 has occurred in the Atlantic sector (Graham et al. 2017); Moore (2016) argues that this is consistent with reduced seaice in the Nordic seas, which shifts the warm air reservoir northwards and facilitates the poleward transport of this heat by weather systems.

\subsection{Origins of winter AA forcing}

For the Beaufort-Chukchi Seas, a wavetrain emanating from the tropics is responsible for the anomalous high over Alaska, evident in Z500 anomalies (Fig. 9c) and in agreement with Hartmann (2015), who links patterns of Pacific sea-surface temperature variability, ultimately originating in the tropical west Pacific, to the anomalous ridging over western North America, with higher temperatures over Alaska. Similarly a tropical wavetrain is evident prior to the high AAI event in the East Siberian-Laptev sector (Fig. 9b), reminiscent of that in Yoo et al. (2011), their Fig. 4. High AAI in the East Siberian Laptev sector appear to be associated with a tropical influence via the wavetrain and strong high AAI events here have a mean ENSO value of - 0.77. On the other hand, no tropical wavetrains are evident for high AAI events in other regions. While Ding et al. (2014) find a similar tropical wavetrain impacting on Arctic warming over Greenland, their results were based on annual mean values, and no such pattern is found here using seasonal daily data. This tropical origin of regional Arctic warming is in agreement with previous studies, where a tropical influence is detected in the western Arctic while warming in the eastern Arctic is associated with storms from the North Atlantic (Ye and Jung 2019). High AAI events in the Barents-Kara Seas are preceded by positive NAO conditions over the Atlantic, with a stronger, northwards-displaced storm-track guiding cyclones into the Arctic. The AWB shown in Fig. 9a is in agreement with other research (Woollings et al. 2008; Liu and Barnes 2015) indicating increased frequency of AWB with the positive phase of the NAO. High AAI events in the Canadian Archipelago on the other hand are preceded by a negative NAO, with a weaker storm track and CWB, suggesting high AAI events in the Archipelago and the BarentsKara Seas are mutually exclusive. The nature of the RWB has been shown to be related to jet stream latitude: when the jet is shifted poleward (equatorward), AWB (CWB) is more frequent, with a corresponding decrease in wave breaking in the opposite direction (Liu and Barnes 2015). As the wave breaking develops in the lead period to extreme high AAI events, jet latitude variability likely influences the location of Arctic warming. 
High AAI events in the Greenland Sea are preceded by a pattern similar to the positive phase of the Scandinavian teleconnection pattern (SCA) (Barnston and Livezey 1987, Eurasia-1 pattern) with high Z500 anomalies over Scandinavia, with AWB, again pushing storms into the Arctic through the Norwegian Seas. It is notable that for all Arctic sectors, high AAI events are associated with positive Z500 anomalies to the east of the moisture and heat intrusion, in agreement with Woods et al. (2013)

There is considerable debate as to whether AA is locally forced through the reduction of sea-ice, or remotely forced through moisture intrusions from lower latitudes (Park et al. 2015; Woods et al. 2013; Woods and Caballero 2016; Gong et al. 2017). These studies are on seasonal timescales, and here we present evidence to suggest forcing of AAI anomalies from lower latitudes, on synoptic timescales, either from variability of the jet stream and the extratropical storm tracks in the Atlantic, or from tropical forcing in the Pacific. High AAI events are associated with intrusions of moist air into the Arctic, particularly in the Beaufort-Chukchi and Greenland Seas. Here however the drivers of moisture transport have different sources: the tropics and midlatitude atmospheric variability respectively. In each case, SIC can be seen to respond to the thermodynamic forcing. It is a moot point whether reduced SIC in autumn is favouring an increased frequency of these circulation patterns. Crasemann et al. (2017) find low sea ice in autumn favours the development of a positive SCA, which then further reduces the sea ice through the northward transport of moisture and heat in synoptic scale storms. Here, on a synoptic scale, a positive SCA precedes the reduction in SIC by two to three days. However this does not necessarily contradict the influence of autumn turbulent heat fluxes favouring enhanced positive SCA patterns in winter.

Taking a seasonal mean of daily AAI produces the characteristic trend of AA seen on a seasonal basis (Fig. 1). Therefore the synoptic-scale forcing of SIC contributes to interannual SIC variability, and also the intrusion events influence AAI on a seasonal scale, as identified in other studies (e.g. Woods and Caballero 2016; Park et al. 2015). Lee et al. (2017) identify DLR as the dominant source of Arctic warming from analysis of decadal trends. Results here are consistent with this approach. Lee et al. (2017) find that trends in THF switch to positive (upwards). However, this is looking at decadal trends, and the heat fluxes are presented as anomalies. In the present study, during a high AAI event THF become less negative during an event, but the overall effect of increased event persistence and frequency found here will contribute to the trend in increased DLR found in Lee et al. 2017.

AA is not uniform over the Arctic and at any given time the warming centres can be located in different sectors within the Arctic, leading to variations between the sectoral
AAIs. On a daily scale, high and low AAI days occur on different days in different sectors and seasonal mean AAI values show considerable temporal variation between sectors. The interannual correlation of seasonal mean AAIs between sectors is moderate to low, although there are certain years where regions have similar values, for example in winter 1998 all regions and by extension the Arctic as a whole, have a low AAI. This may be related to the then record ENSO event of this year, with concomitant positive temperature anomalies in the lower latitudes which would reduce the AAI. Similarly, interannual patterns of persistence, frequency and intensity of warm and cold events vary between sectors. These results suggest that AA should be regarded as a regional, quite short-lived phenomenon, rather than Arctic-wide at any given time, which helps to explain how a warm Arctic may appear to have different impacts in different regions and at different times, depending on the location of Arctic warming. Warming over the different Arctic regions is associated with different remote forcings both from the tropics and midlatitudes, which explains the often low correlations between regional AAIs: for example, warming over Alaska can be associated with El-Niño teleconnections while high latitude Eurasian warming may be linked to Atlantic teleconnections (e.g. Cullather et al. 2016).

\section{Summary}

Using a daily AAI, we have assessed synoptic-scale Arctic warming, its spatial and temporal variability and examined contributory sources of the warming. The key findings are as follows:

- There are general and often significant increases (decreases) in the persistence, frequency and intensity of synoptic-scale high (low) AAI events during the time period.

- There is considerable regional variability within the Arctic in the timing, magnitude and trends in persistence frequency and intensity of AAI events; the more extreme AAI days, both high and low, are likely to occur over land, rather than over the sea.

- Synoptic-scale high AAI warm Arctic events account for much of the seasonal trends in AA.

- Significant 11-year trends of increasing AA, including persistence, frequency, intensity and seasonal mean AAI, are concentrated in the period 2000-2009, with relatively few significant trends prior and subsequent to this.

- Winter high AAI events are driven primarily by poleward transport of moisture and heat, and downward longwave radiation flux, rather than increased turbulent heat fluxes to the atmosphere as a result of reduced sea-ice. There is 
some decrease in SIC in response to the warming of the Arctic troposphere.

- Winter high AAI events in different Arctic sectors have distinct differences in energy and moisture flux terms prior to and immediately after the peak high AAI event.

- There is clear evidence from Rossby wave breaking and from wavetrain patterns, that indicate a tropical origin for high AAI events in certain regions (BC, ESL), while high AA events in other regions are influenced by midlatitude circulation changes: the poleward transport of heat and moisture by extratropical cyclones, and variations in the latitude of the polar front jetstream which influences the nature of the Rossby wave breaking.

- This study reinforces the view (Gong et al. 2017; Palmer 1993) that interannual changes in AA are due to changes in frequency, persistence and intensity of short-term events in the Arctic rather than slow long-term shifts in the mean state or in the structure of spatial patterns.

Acknowledgements We thank the ECMWF for the prevision of ERA-I reanalysis data. EH thanks the Nansen Center for funding a research visit that helped to facilitate this collaboration. LC was supported by the Research Council of Norway through the EuropeWeather project (No. 231322/F20). We thank the three anonymous reviewers for their comments, which greatly improved the manuscript.

\section{Funding}

Open Access This article is licensed under a Creative Commons Attribution 4.0 International License, which permits use, sharing, adaptation, distribution and reproduction in any medium or format, as long as you give appropriate credit to the original author(s) and the source, provide a link to the Creative Commons licence, and indicate if changes were made. The images or other third party material in this article are included in the article's Creative Commons licence, unless indicated otherwise in a credit line to the material. If material is not included in the article's Creative Commons licence and your intended use is not permitted by statutory regulation or exceeds the permitted use, you will need to obtain permission directly from the copyright holder. To view a copy of this licence, visit http://creativecommons.org/licenses/by/4.0/.

\section{References}

Barnston AG, Livezey RE (1987) Classification, seasonality and persistence of low-frequency atmospheric circulation patterns. Mon Wea Rev 115:1083-1126

Benjamini Y, Hochberg Y (1996) Controlling the false discovery rate: a practical and powerful approach to multiple testing. J R Stat Soc B57:289-300

Chen L, Francis JA, Hanna E (2018) The "Warm-Arctic/Cold-continents" pattern during 1901-2010. Int J Climatol. 2018:1-10. https ://doi.org/10.1002/joc.5725

Cohen J, Screen JA, Furtado JC, Barlow M, Whittleston D, Coumou D, Francis J, Dethloff K, Entekhabi D, Overland J, Jones J (2014) Recent Arctic amplification and extreme mid-latitude weather. Geosci, Nat. https://doi.org/10.1038/ngeo2234
Cohen J, Zhang X, Francis J, Jung T, Kwok R, Overland J, Tayler PC, Lee S, Laliberte F, Feldstein S, Maslowski W, Henderson G, Stroeve J, Coumou D, Handorf D, Semmler T, Ballinger T, Hell M, Kretschmer M, Vavrus S, Wang M, Wang S, Wu Y, Vihma T, Bhatt U, Ionita M, Linderholm H, Rigor I, Routson C, Singh D, Wendisch M, Smith D, Screen J, Yoon J, Peings Y, Chen H, Blackport R (2018) Arctic change and possible influence on mid-latitude climate and weather. US CLIVAR Rep. https://doi. org/10.5065/D6TH8KGW

Cowtan K, Way RG (2014) Coverage bias in the HadCRUT4 temperature series and its impact on recent temperature trends. Q J Roy MeteorolSoc 140:1935-1944. https://doi.org/10.1002/qj.2297

Crasemann B, Handorf D, Jaiser R, Dethloff K, Nakamura T, Ukita J, Yamazaki K (2017) Can preferred atmospheric circulation patterns over the North Atlantic-Eurasian region be associated with arctic sea ice loss? Polar Sci 14:9-20. https://doi.org/10.1016/j. polar.2017.09.002

Cullather RI, Lim Y-K, Boisvert LN, Brucker L, Lee JN, Nowicki SMJ (2016) Analysis of the warmest Arctic winter, 2015-2016. Geophys Res Lett. https://doi.org/10.1002/2016GL071228

Davy R, Chen L, Hanna E (2018) Arctic amplification metrics. Int J Climatol. https://doi.org/10.1002/joc.5675

Dee DP et al (2011) The ERA-Interim reanalysis: configuration and performance of the data assimilation system. QJR Meteorol Soc 137:553-597. https://doi.org/10.1002/qj.828

Derksen C, Brown R (2012) Spring snow cover extent reductions in the 2008-2012 period exceeding climate model projections. Geophys Res Lett 39:L19504. https://doi.org/10.1029/2012GL053387

Deser C, Walsh JE, Timlin MS (2000) Arctic sea ice variability in the context of recent atmospheric circulation trends. J Clim 13:617-633

Ding Q, Wallace JM, Battisti DS, Steig EJ, Gallant AJE, Kim H-J, Geng L (2014) Tropical forcing of the recent rapid Arctic warming in northeastern Canada and Greenland. Nature 509:209-213. https://doi.org/10.1038/nature13260

Ding Q, Schweiger A, L'Heureux M, Battisti DS, Po-Chedley S, Johnson NC, Blanchard-Wrigglesworth E, Harnos K, Zhang Q, Eastman R, Steig EJ (2017) Influence of high-latitude atmospheric circulation changes on summertime Arctic sea ice. Nat Clim Chge 7:289-295. https://doi.org/10.1038/NCLIMATE32 41

Francis JA, Vavrus SJ (2015) Evidence for a wavier jet stream in response to rapid Arctic warming. Environ Res Lett 10:014005. https://doi.org/10.1088/1748-9326/10/1/104005

Gong T, Feldstein S, Lee S (2017) The role of downward infrared radiation in the recent Arctic winter warming trend. J Clim 30:49374949. https://doi.org/10.1175/JCLI-D-16-0180.1

Graham RM, Cohen L, Petty AA, Boisvert LN, Rinke A, Hudson SR, Nicolaus M, Granskog MA (2017) Increasing frequency and duration of Arctic winter warming events. Geophys Res Lett 44:69746983. https://doi.org/10.1002/2017GL073395

Graversen RG, Wang M (2009) Polar amplification in a coupled climate model with locked albedo. Cliim Dyn 33:629-643. https://doi. org/10.1007/s00382-009-0535-6

Graversen RG, Mauritsen T, Tjernstrom M, Kallen E, Svensson G (2008) Vertical structure of recent Arctic Warming. Nature 451:53-56. https://doi.org/10.1038/nature06502

Graversen RG, Langen PI, Mauritsen T (2014) Polar amplification in CCSM4: contributions from the lapse rate and surface albedo feedbacks. J Clim 27:4433-4450

Hao M, Luo Y, Lin Y, Zhao Z, Wang L, Huang J (2019) Contribution of atmospheric moisture transport to winter Arctic warming. Int J Climatol. https://doi.org/10.1002/joc.5982

Hao M, Luo Y, Lin Y, Zhao Z, Wang L, Huang J (2019) Contribution of atmospheric moisture transport to winter Arctic warming. Int J Climatol. https://doi.org/10.1002/joc.5982 
Hanna E, Hall RJ, Overland JE (2017) Can Arctic warming influence UK extreme weather? Weather 72:346-352. https://doi. org/10.1002/wea.2981

Hanna E, Hall RJ, Cropper TE, Ballinger TJ, Wake L, Mote T, Cappelen J (2018a) Greenland Blocking Index daily series 18512015: analysis of changes in extremes and links with North Atlantic and UK climate variability and change. Int J Climatol. https:// doi.org/10.1002/joc.5516

Hanna E, Fettweis X, Hall, RJ (2018b) Brief communication: Recent changes in summer Greenland blocking captured by none of the CMIP5 models. The Cryosphere 12:3287-3292. https://doi. org/10.5194/tc-12-3287-2018

Hansen J, Ruedy R, Sato M, Lo K (2010) Global surface temperature change. Rev Geophys 48:RG4004. https://doi.org/10.1029/2010R G000345

Hartmann DL (2015) Pacific sea surface temperature and the winter of 2014. Geophys Res Lett 42:1894-1902. https://doi. org/10.1002/2015GL 063083

Kidston J, Scaife AA, .Hardiman SC, Mitchell DM, Butchart N, Baldwin MP, Gray LJ (2015) Stratospheric influence on tropospheric jet streams, storm tracks and surface weather. Nat Geosci 8:433440. https://doi.org/10.1038/NGERO2424

Kim B-M, Hong J-Y, Jun S-Y, Zhang X, Kwon H, Kim S-J, Kim J-H, Kim S-W, Kim H-K (2017a) Major cause of unprecedented Arctic warming in January 2016: critical role of an Atlantic windstorm. Sci Rep 7:40051. https://doi.org/10.1038/srep40051

Kim H-S, Choi Y-S, Kim J-H, Kim W-M (2017b) Multiple aspects of northern hemispheric wintertime cold extremes as revealed by Markov chain analysis. Asia-Pac J Atmos Sci 53(1):51-61. https ://doi.org/10.1007/s13143-017-0004-9

Kobayashi S, Ota Y, Harada Y, Ebita A, Moriya M, Onoda H, Onogi K, Kamahori H, Kobayashi C, Endo H, Miyaoka K, Takahashi K (2015) The JRA-55 reanalysis: general specifications and basic chararcteristics. J Meteor Soc Japan 94:269-302. https://doi. org/10.2151/jmsj.2016-015

Laîné A, Yoshimori M, Abe-Ouchi A (2016) Surface arctic amplification factors in CMIP5 models: land and oceanic surfaces and seasonality. J Clim 29:3297-3316. https://doi.org/10.1175/ JCLI-D-15-0497.1

Lee S, Gong T, Feldstein SB, Screen JA, Simmonds I (2017) Revisiting the cause of the 1989-2009 Arctic surface warming using the surface energy budget: downward infrared radiation dominates the surface fluxes. Geophys Res Lett 44:10654-10661. https:// doi.org/10.1002/2017GL075375

Lindsay R, Wensnahan M, Schweiger A, Zhang J (2014) Evaluation of seven different atmospheric reanalysis products in the Arctic. J Clim 27:2588-2606. https://doi.org/10.1175/JCLI-D-13-00014.1

Liu C, Barnes EA (2015) Extreme moisture transport into the Arctic linked to Rossby wave breaking. J Geophys Res Atmos 120:37743788. https://doi.org/10.1002/2014JD022796

McCusker KE, Fyfe JC, Sigmond M (2016) Twenty-five winters of unexpected Eurasian cooling unlikely due to Arctic sea-ice loss. Nat Geosci 9(11):838-842. https://doi.org/10.1038/NGEO2820

Morice CP, Kennedy JJ, Rayner NA, Jones PD (2012) Quantifying uncertainties in global and regional temperature change using an ensemble of observational estimates: the HadCRUT4 dataset. J Geophys Res Atmos 117:D08101. https://doi.org/10.1029/2011J D017187

Moore GWK (2016) The December 2015 North Pole warming event and the increasing occurrence of such events. Sci Rep 6:39084. https://doi.org/10.1038/srep39084

Overland JE, Wang M (2016) Recent extreme Arctic temperatures are due to a split polar vortex. J Clim 29:5609-5616. https://doi. org/10.1175/JCLI-D-16-0320.1
Overland JE, Wood KR, Wang M (2011) Warm Arctic-cold continents: climate impacts of the newly open Arctic Sea. Polar Res 30:15787. https://doi.org/10.3402/polar.v30i0.15787

Overland JE, Francis JA, Hanna E, Wang M (2012) The recent shift in early summer Arctic atmospheric circulation. Geophys Res Lett 39:L19804. https://doi.org/10.1029/2012GL053268

Overland J, Francis, JA, Hall, R, Hanna, E, Kim , S.-J, Vihma T (2015) The melting arctic and midlatitude weather patterns: are they connected? J Clim 28:7917-7932. https://doi.org/10.1175/ JCLI-D-14-00822.1

Overland JE, Hanna E, Hanssen-Bauer I, Kim S-J, Walsh JE, Wang M, Bhatt US, Thoman RL (2018) Surface air temperature, Arctic Report Card 2018, https://www.arctic.noaa.gov/Report-Card/ Report-Card-2018

Park H-S, Lee S, Son S-W, Feldstein SB, Kosaka Y (2015) The impact of poleward moisture and sensible heat flux on Arctic winter sea ice variability. J Clim 28:5030-5040. https://doi.org/10.1175/ JCLI-D-15-0074.1

Pithan F, Mauritsen T (2014) Arctic amplification dominated by temperature feedbacks in contemporary climate models. Nat Geosci 7:181-184. https://doi.org/10.1038/NGEO2071

Screen JA (2017) Simulated atmospheric response to regional and panArctic sea ice loss. J Clim 30:3945-3962. https://doi.org/10.1175/ JCLI-D-16-0197.1

Screen JA, Simmonds I (2010) Increasing fall-winter energy loss from the Arctic Ocean and its role in Arctic temperature amplification. Geophys Res Lett 37:L16707. https://doi.org/10.1029/2010G L044136

Sen PK (1968) Estimates of the regression coefficient based on Kendall's Tau. J Am Stat Assoc 63(324):1379-1389

Serreze MC, Francis JA (2006) The Arctic amplification debate. Clim Change 76:241-264. https://doi.org/10.1007/s10584-005-9017-y

Serreze MC, Barry RG (2011) Processes and impacts of Arctic amplification: a research synthesis. Glob Planet Change 77:85-96. https ://doi.org/10.1016/j.gloplacha.2011.03.004

Simmons AJ, Poli P (2014) Arctic warming in ERA-Interim and other analyses. Quart J Roy Meteorol Soc 141:1147-1152. https://doi. org/10.1002/qj.2422

Stroeve J, Notz D (2018) Changing state of Arctic sea ice across all seasons. Env Res Lett 13: 103001, https://doi.org/10.1088/17489326/aade56

Strong C, Magnusdottir G (2008) Tropospheric Rossby wave breaking and the NAO/NAM. J Atm Sci 65(9):2861-2876

Thorncroft CD, Hoskins BJ, McIntyre ME (1993) Two paradigms of baroclinic-wave life-cycle behaviour. Quart J Roy Met Soc 119:17-55

Vavrus SJ, Wang F, Martin JE, Francis JA, Peings Y, Cattiaux J (2017) Changes in North American atmospheric circulation and extreme weather: influence of Arctic amplification and Northern Hemisphere snow cover. J Clim 30:4317-4333. https://doi.org/10.1175/ JCLI-D-16-0762.1

Wilks DS (2011) Statistical methods in the atmospheric sciences, 2nd edn. Academic Press, New York, p 676

Wilton DJ, Jowett A, Hanna E, Bigg GR, van den Broeke MR, Fettweis X, Huybrechts P (2017) High resolution (1 km) positive degreeday modelling of Greenland ice sheet surface mass balance, 1870-2012 using reanalysis data. J Glac 63:176-193. https://doi. org/10.1017/jog.2016.133

Woods C, Caballero R (2016) The role of moist intrusions in winter Arctic warming and sea ice decline. J Clim 29:4473-4485. https ://doi.org/10.1175/JCLI-D-15-0773.1

Woods C, Caballero R, Svensson G (2013) Large-scale circulation associated with moisture intrusions into the Arctic during winter. Geophys Res Lett 40:4717-4721. https://doi.org/10.1002/ grl.50912 
Woollings T, Hoskins B, Blackburn M, Berrisford P (2008) A new Rossby wave-breaking interpretation of the North Atlantic Oscillation. J Atmos Sci 65(2):609-626

Woollings T, Barriopedro D, Methven J, Son S-W, Martius O, Harvey B, Sillmann J, Lupo AR, Seneviratne S (2018) Blocking and its response to climate change. Curr Clim Change Rep 4:287-300

Ye K, Jung T (2019) How strong is influence of the tropics and midlatitudes on the Arctic atmospheric circulation and climate change? Geophys Res Lett, https://doi.org/10.1029/2019GL082391

Yoo C, Feldstein S, Lee S (2011) Geophys Res Lett 38:L24804. https ://doi.org/10.1029/2011GL049881

Zhang X, Vincent LA, Hogg WD, Niitsoo A (2000) Temperature and precipitation trends in Canada during the 20th century. Atmos Ocean 38(3):395-429
Zhong L, Hua L, Luo D (2018) Local and external moisture sources for the Arctic warming over the Barents-Kara Seas. J Clim 31:19631982. https://doi.org/10.1175/JCLI-D-17-0203.1

Publisher's Note Springer Nature remains neutral with regard to jurisdictional claims in published maps and institutional affiliations. 